\title{
An anti-inflammatory diet as treatment for inflammatory bowel disease: a case series report
}

\author{
Barbara C Olendzki ${ }^{*}$, Taryn D Silverstein ${ }^{2}$, Gioia M Persuitte ${ }^{1}$, Yunsheng Ma ${ }^{1}$, Katherine R Baldwin ${ }^{3}$ \\ and David Cave ${ }^{2}$
}

\begin{abstract}
Background: The Anti-Inflammatory Diet (IBD-AID) is a nutritional regimen for inflammatory bowel disease (IBD) that restricts the intake of certain carbohydrates, includes the ingestion of pre- and probiotic foods, and modifies dietary fatty acids to demonstrate the potential of an adjunct dietary therapy for the treatment of IBD.

Methods: Forty patients with IBD were consecutively offered the IBD-AID to help treat their disease, and were retrospectively reviewed. Medical records of 11 of those patients underwent further review to determine changes in the Harvey Bradshaw Index (HBI) or Modified Truelove and Witts Severity Index (MTLWSI), before and after the diet.

Results: Of the 40 patients with IBD, 13 patients chose not to attempt the diet (33\%). Twenty-four patients had either a good or very good response after reaching compliance (60\%), and 3 patients' results were mixed (7\%). Of those 11 adult patients who underwent further medical record review, 8 with $C D$, and 3 with $U C$, the age range was 19-70 years, and they followed the diet for 4 or more weeks. After following the IBD-AID, all (100\%) patients were able to discontinue at least one of their prior IBD medications, and all patients had symptom reduction including bowel frequency. The mean baseline HBI was 11 (range 1-20), and the mean follow-up score was 1.5 (range $0-3$ ). The mean baseline MTLWSI was 7 (range 6-8), and the mean follow-up score was 0 . The average decrease in the HBI was 9.5 and the average decrease in the MTLWSI was 7.
\end{abstract}

Conclusion: This case series indicates potential for the IBD-AID as an adjunct dietary therapy for the treatment of IBD. A randomized clinical trial is warranted.

Keywords: Diet, Inflammatory bowel disease, Nutrition

\section{Introduction}

Crohn's disease (CD) and ulcerative colitis (UC) are two chronic inflammatory diseases of the gastrointestinal tract, collectively known as inflammatory bowel disease (IBD). Each is distinct in its presentation and course of disease, and both are chronically relapsing illnesses. Despite histological differences between the two diseases, dietary therapy (with the exception of known efficacy of enteral therapy and $\mathrm{CD}$ ) has often been similar for both [1], involving options that include increased fluids,

\footnotetext{
* Correspondence: Barbara.olendzki@umassmed.edu

${ }^{1}$ Division of Preventive and Behavioral Medicine, University of Massachusetts Medical School, 55 Lake Ave North, Shaw Building, Worcester MA, USA Full list of author information is available at the end of the article
}

avoidance of fatty foods, dietary fiber, and dairy products if lactose intolerant. Others have ingested nothing by mouth for a period of time, and used tube feeding with elemental diets [2]. Presently, an alteration of the intestinal microbiome is believed to be a major factor in the pathogenesis of IBD, and this change provides a possible pathway for dietary manipulations of the microbiome that may reduce inflammation in these conditions $[3,4]$.

The goals for treatment of IBD are the induction of remission, maintenance of remission, reduction in the need for long-term use of corticosteroids, improved quality of life, and improved prognosis. The mainstays of current treatment comprise of anti-inflammatory agents including corticosteroids, immunomodulators, and biologic agents.

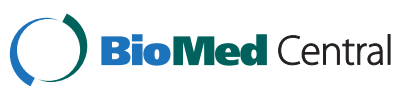


There are surgical options including colectomy, which while curative for patients with UC, can result in a pouch or end ileostomy in approximately $30 \%$ of patients [5]. Neither of these surgical options is without complications and up to $70 \%$ of patients with a pouch may develop pouchitis [6,7]. An even higher percentage of $C D$ patients need surgery, with upward of $80 \%$ of patients requiring surgical resection that is not necessarily curative [5].

Until recently, the investigation of nutritional approaches in treating the diseases have been largely limited to the use of enteral and total parenteral nutrition with the aim of providing bowel rest $[8,9]$. Dietary whole food recommendations for CD and UC are poorly developed, even though patients often ask for advice with their diet [10]. To prepare clinicians for the complex management of patients with IBD, Brown et al. published dietary guidelines to fill this gap, [2] compiling a summary of suggestions from reputable organizations, concluding that no specific diet currently exists for patients with IBD. Most dietary guidelines, though varied in scope and complexity, indicate that limiting lactose, excess fat, excess carbohydrates, and reducing fiber in the diet is necessary, particularly during flares of disease [2]. Mineral and vitamin supplementation may or may not assist with nutrient deficiencies and malabsorption. In addition, many patients also experience other food intolerances $[11,12]$. To provide a dietary therapy approach addressing nutrient adequacy, malabsorption issues, and symptoms, we developed the IBD-AntiInflammatory Diet, or IBD-AID [13-15]. The diet was offered to patients who were refractory to pharmacological therapy, or treatment was not as effective as desired. This is a retrospective case series to demonstrate the beneficial effects of the IBD-AID on a small number of patients.

\section{Materials and methods \\ Patients}

Forty patients received instructions for the diet, 37 saw the nutritionist, and 3 were seen only by gastroenterologists. Medical records review was approved by the Institutional Review Board (IRB) of the University of Massachusetts Medical School. Eligibility for this further review included seeing an IRB-approved gastroenterologist and dietitian in clinic, endoscopically-diagnosed IBD and failure of drug treatment, persistent symptoms, or reluctance to proceed with other options (Table 1). Medical records of the eleven patients for whom we had complete data and used the IBD-AID to help treat their disease were retrospectively reviewed and their progress was assessed using the Harvey Bradshaw (HBI) and Modified Truelove and Witts Severity Index (MTLWSI) scoring systems [16,17] applied before and during the use of the IBD-AID. Review of these patients included clinic notes from gastroenterologists, primary care physicians, nutritionists, surgeons, hospital admission and discharge summaries, as well as laboratory data (i.e.; hematocrit, albumin, erythrocyte sedimentation rate (ESR), C-reactive protein (CRP), drug concentration levels, imaging studies, and endoscopic evaluation. An HBI for CD patients or MTLWSI for UC patients was included or estimated from information provided by clinic notes. The data was compared before dietary treatment, and evaluated 1-3 months after patients stated they followed the IBD-AID.

Table 1 Participant demographics, medications, and disease indices

\begin{tabular}{|c|c|c|c|c|c|c|c|}
\hline \multirow{2}{*}{$\begin{array}{l}\text { Age } \\
39\end{array}$} & \multirow{2}{*}{$\begin{array}{l}\text { Sex } \\
F\end{array}$} & \multirow{2}{*}{$\begin{array}{l}\text { Disease } \\
C D\end{array}$} & \multirow{2}{*}{$\begin{array}{l}\text { Prior treatment includes } \\
\text { ASA, IM, B }\end{array}$} & \multirow{2}{*}{$\begin{array}{l}\text { Recent treatment } \\
A S A+\mid B D-A I D\end{array}$} & \multicolumn{2}{|c|}{ HBI/MTLWSI before } & \multirow{2}{*}{$\begin{array}{l}\text { HBI/MTLWSI after } \\
3\end{array}$} \\
\hline & & & & & $\mathrm{HBI}$ & 12 & \\
\hline 47 & $F$ & $C D$ & $S, I M, B$ & $S($ taper $)+\mid B D-A I D$ & $\mathrm{HBI}$ & 9 & 2 \\
\hline 39 & $\mathrm{~F}$ & CD & S,IM & $I M+\mid B D-A I D$ & $\mathrm{HBI}$ & 12 & 2 \\
\hline 24 & $\mathrm{~F}$ & CD & S,ASA, IM, B & S(taper) IM + IBD-AID & $\mathrm{HBI}$ & 15 & 0 \\
\hline 39 & M & $C D$ & $\mathrm{IM}, \mathrm{B}$ & $\mathrm{IBD}+\mathrm{AID}$ & $\mathrm{HBI}$ & 20 & 0 \\
\hline 40 & $M$ & CD & S,ASA, IM & $I M+\mid B D-A I D$ & $\mathrm{HBI}$ & 15 & 2 \\
\hline 41 & $M$ & CD & ASA, IM & $I M+\mid B D-A I D$ & $\mathrm{HBI}$ & 4 & 2 \\
\hline 37 & $F$ & $C D$ & S,ASA, B, elemental diet & $B+\mid B D-A I D$ & $\mathrm{HBI}$ & 1 & 1; histologic remission \\
\hline 69 & $M$ & UC & ASA, IM, B & $A S A, I M+\mid B D-A I D$ & MTL & & 2; improved \\
\hline 19 & $\mathrm{~F}$ & UC & $S, A S A, I M, B$ & ASA, IBD-AID & MTL & & 0 \\
\hline 70 & $\mathrm{~F}$ & UC & ASA, IM, B & $B+\mid B D-A I D$ & MTL & & 0 \\
\hline
\end{tabular}




\section{The diet}

The goal of the IBD-AID is to assist with a decreased frequency and severity of flares, obtain and maintain remission. Dysbiosis, or altered bacterial flora, is one of the theories behind the development of IBD-AID, in that certain carbohydrates in the lumen of the gut provide pathogenic bacteria a substrate on which to proliferate [17-21]. The IBD-AID has five basic components: the first of which is the modification of certain carbohydrates, (including lactose, and refined or processed complex carbohydrates) the second places strong emphasis on the ingestion of pre- and probiotics (e.g.; soluble fiber, leeks, onions, and fermented foods) to help restore the balance of the intestinal flora [22-25], and the third distinguishes between saturated, trans, mono- and polyunsaturated fats [26-29], the fourth encourages a review of the overall dietary pattern, detection of missing nutrients, and identification of intolerances. The last component modifies the textures of the foods (e.g.; blenderized, ground, or cooked) as needed (per patient symptomology, see Table 2) to improve absorption of nutrients and minimize intact fiber. The phases indicated in Table 2 are examples of the modification of texture complexity, so that dietitian and patient can expand the diet as the patient's tolerance and absorption improves. Some sensitivities common to many patients (not just those with IBD), are eased through supplementation of digestive enzymes or avoidance. A senior dietitian advised the patient and either family or spouse regarding the details of the diet during regular clinic visits. Patients taking supplements (probiotics, vitamin/minerals, omega-3 fatty acids) were advised to continue or discontinue, depending on the needs of the individual and the dietary intake.

The IBD-AID consists of lean meats, poultry, fish, omega-3 eggs, particular sources of carbohydrate, select fruits and vegetables, nut and legume flours, limited aged cheeses (made with active cultures and enzymes), fresh cultured yogurt, kefir, miso and other cultured products (rich with certain probiotics) and honey. Prebiotics, in the form of soluble fiber (containing betaglucans and inulin, such as bananas, oats, blended chicory root, and flax meal) are suggested. In addition, the patient is advised to begin at a texture phase of the diet matching with symptomology, starting with phase one if in an active flare. Many patients require foods to be softened and textures mechanically altered by pureeing the foods, and avoiding foods with stems and seeds when starting the diet (see phases 1-3 of Table 2), as intact fiber can be problematic for those with strictures and highly active mucosal inflammation. Some patients will require lifelong avoidance of intact fiber. Food irritants are not limited to intact fiber, but may include certain foods, processing agents and flavorings to which IBD patients may be reactive.
For the purposes of this study, compliance was determined by food records (patient self-report), and included all food components for the duration of the study. After the first visit with the dietitian, patients were asked to keep detailed food records, along with time and recording of symptoms (on a scale of 0-5), with follow-up appointments occurring 2-3 weeks after the initial consult. Symptoms included a subjective assessment of bloating, pain, diarrhea, urgency, bleeding, and fatigue. Other influences to health that were recorded by patients included perceived stress, and origin of food intake. Most patients indicated difficulty in understanding and adhering to the diet initially, while tracking trends of symptomatic progress. The form and type of foods recommended in the beginning were based on the severity of symptoms reported, with the goal to deliver nutrients even if the patient started the diet while in a flare. As symptoms improved, patients were advanced to more whole foods, but within the guidelines of the IBD-AID. One of the patients did not improve within the first 2-3 weeks, and the diet was reviewed for foods of intolerance. In this case, the patient who continued to experience symptoms (loose bowels, dyspepsia and bloating) improved through stronger adherence and changing the texture/form of foods consumed. All patients were then advanced cautiously as symptoms improved.

\section{Clinical assessment}

The HBI was used to assess study patients with $\mathrm{CD}$. The $\mathrm{HBI}$ is a simplified, less cumbersome alternative to the Crohn's Disease Activity Index (CDAI), and is designed to make data collection and calculation easier, with greater application to clinical practice since it is based on the last 24 hours of data [17]. A prospective study of 112 patients with Crohn's disease showed that the CDAI and HBI scores were highly correlated $(r=0.93)$ [17]. Our analyses define HBI remission as an HBI score of less than or equal to 4 points, and HBI response as a decrease in HBI score of greater than or equal to 3 points. The MTLWSI was used for patients with UC. First described in 1990 by Lichtiger and colleagues [16] in a trial for the treatment of UC, the MTLWSI includes a scoring system ranging from $0-21$ points, and clinical response is defined as a decrease from the baseline score of $50 \%$, or greater or less than 10 on 2 consecutive days. Clinical remission criteria was determined by a MTWSI of less than or equal to 2 , and clinical response was defined as a reduction from baseline in the MTWSI of greater than or equal to 2 points [30].

\section{Results}

Out of the original 40 patients, 37 were seen by the dietitian. Of those, 13 did not attend any follow-up visits. Three had an ambivalent or negative response to 


\section{Table 2 IBD-AID food phase chart}

\begin{tabular}{|c|c|c|c|c|}
\hline \multirow[t]{2}{*}{ Phase type } & \multirow{2}{*}{$\begin{array}{l}\text { Phase I } \\
\text { Soft, well-cooked or cooked then } \\
\text { pureed foods, no seeds }\end{array}$} & \multirow{2}{*}{$\begin{array}{l}\text { Phase II } \\
\text { Soft Textures: well-cooked or pureed } \\
\text { foods, no seeds, choose floppy or } \\
\text { tender foods }\end{array}$} & \multirow{2}{*}{$\begin{array}{l}\text { Phase III } \\
\text { May still need to avoid stems, choose } \\
\text { floppy greens or other greens depending } \\
\text { on individual tolerance }\end{array}$} & \multirow{2}{*}{$\begin{array}{l}\text { Phase IV } \\
\text { If in remission with no strictures }\end{array}$} \\
\hline & & & & \\
\hline \multirow[t]{2}{*}{ Vegetables } & $\begin{array}{l}\text { Butternut Squash, Pumpkin, Sweet } \\
\text { Potatoes, Onions }\end{array}$ & $\begin{array}{l}\text { Carrots, Zucchini, Eggplant, Peas, Snow } \\
\text { peas, Spaghetti squash, Green beans, } \\
\text { Yellow beans, Microgreens ( } 2 \text { week old } \\
\text { baby greens), Watercress, Arugula, Fresh } \\
\text { flat leaf parsley and cilantro, Seaweed, } \\
\text { Algae }\end{array}$ & $\begin{array}{l}\text { Butter lettuce, Baby spinach, Peeled cucumber, } \\
\text { Olives, Leeks Bok Choy, Bamboo shoots, Collard } \\
\text { greens, Beet greens, Sweet peppers, Kale, } \\
\text { Fennel bulb }\end{array}$ & $\begin{array}{l}\text { Artichokes, Asparagus, Tomatoes, } \\
\text { Lettuce, Brussels sprouts, Beets, } \\
\text { Cabbage, Kohlrabi, Rhubarb, Pickles, } \\
\text { Spring onions, Water chestnuts, } \\
\text { Celery, Celeriac, Cauliflower, Broccoli, } \\
\text { Radish, Green pepper, Hot pepper }\end{array}$ \\
\hline & $\begin{array}{l}\text { Pureed vegetables: Mushrooms, } \\
\text { Phase II vegetables (pureed) }\end{array}$ & Pureed vegetables: all except cruciferous & Pureed vegetables: all from Phase IV, Kimchi & \\
\hline Fruits & Banana, Papaya, Avocado, Pawpaw & $\begin{array}{l}\text { Watermelon (seedless), Mangoes, Honeydew, } \\
\text { Cantaloupe, May need to be cooked: Peaches, } \\
\text { Plums, Nectarines, Pears, (Phase III fruits are } \\
\text { allowed if pureed and seeds are strained out) }\end{array}$ & $\begin{array}{l}\text { Strawberries, Cranberries, Blueberries, Apricots, } \\
\text { Cherries, Coconut, Lemons, Limes, Kiwi, Passion } \\
\text { fruit, Blackberries, Raspberries, Pomegranate } \\
\text { (May need to strain seeds from berries) }\end{array}$ & $\begin{array}{l}\text { Grapes, Grapefruit, Oranges, Currants, } \\
\text { Figs, Dates, Apples (best cooked), } \\
\text { Pineapple, Prunes }\end{array}$ \\
\hline Meats and fish & $\begin{array}{l}\text { All fish (no bones), Sardines (small } \\
\text { bones ok), Turkey and ground beef, } \\
\text { Chicken, Eggs }\end{array}$ & Scallops & Lean cuts of Beef, Lamb, Duck, Goose & Shrimp, Prawns, Lobster \\
\hline Non dairy unsweetened & $\begin{array}{l}\text { Coconut milk, Almond milk, Oat } \\
\text { milk, Soy milk }\end{array}$ & & & \\
\hline Dairy, unsweetened & Yogurt, Kefir & $\begin{array}{l}\text { Farmers cheese (dry curd cottage cheese), } \\
\text { Cheddar cheese }\end{array}$ & Aged cheeses & \\
\hline Nuts/Oils/Legumes/Fats & $\begin{array}{l}\text { Miso (refrigerated), Tofu, Olive oil, } \\
\text { Canola oil, Flax oil, Hemp oil, } \\
\text { Walnut oil, Coconut oil }\end{array}$ & $\begin{array}{l}\text { Almond flour, Peanut flour, Soy flour, Sesame } \\
\text { oil, Grapeseed oil, Walnut oil, Pureed nuts, } \\
\text { Safflower oil, Sunflower oil }\end{array}$ & $\begin{array}{l}\text { Whole nuts, Soybeans, Bean flours, Nut butters, } \\
\text { Well-cooked lentils (pureed), Bean purees } \\
\text { (e.g. hummus) }\end{array}$ & Whole beans and lentils \\
\hline Grains & $\begin{array}{l}\text { Ground flax or Chia Seeds (as } \\
\text { tolerated) }\end{array}$ & Steel cut oats (well-cooked as oatmeal) & Rolled well-cooked oats & \\
\hline Spices & $\begin{array}{l}\text { Basil, Sage, Oregano, Salt, Nutmeg, } \\
\text { Cumin, Cinnamon, Turmeric, Saffron, } \\
\text { Mint, Bay leaves, Tamari (wheat free } \\
\text { soy sauce), Fenugreek tea, Fennel } \\
\text { tea, Vanilla }\end{array}$ & $\begin{array}{l}\text { Dill, Thyme, Rosemary Tarragon, Cilantro, Basil, } \\
\text { Parsley }\end{array}$ & $\begin{array}{l}\text { Mint, Ginger, Garlic (minced), Paprika, Chives, } \\
\text { Daikon, Mustard }\end{array}$ & $\begin{array}{l}\text { Wasabi, Tamarind, Horseradish, } \\
\text { Fenugreek, Fennel }\end{array}$ \\
\hline Sweeteners & $\begin{array}{l}\text { Stevia, Maple syrup, Honey (local), } \\
\text { Unsweetened fruit juice }\end{array}$ & Lemon and lime juice & & \\
\hline Misc. & $\begin{array}{l}\text { Capsule or liquid supplements, } \\
\text { Cocoa powder }\end{array}$ & $\begin{array}{l}\text { Baking powder (no cornstarch), Baking soda, } \\
\text { Unflavored gelatin }\end{array}$ & Ghee, Light mayonnaise, Vinegar & $\begin{array}{l}\text { Ketchup (sugar free), Hot sauce } \\
\text { (sugar free) }\end{array}$ \\
\hline
\end{tabular}


the diet, and 24 had a good or very good response to the diet, as measured by self-report of symptoms and compliance with the diet through food records. Of the patients reporting improvement, they were all able to reach greater than $70 \%$ compliance to the diet. Of the 3 patients ( 2 with $\mathrm{UC}$, 1 with $\mathrm{CD}$ ) with ambivalent or negative response, 2 were diagnosed with Clostridium Difficile (C-diff), and the other (UC) patient's response is unattributable.

The 11 patients, who met eligibility by IRB and had complete data, underwent medical record review: 8 have $\mathrm{CD}, 3$ have UC, and age range was $19-70$ years (see Table 1). All patients used the diet for at least 4 weeks. Before the dietary intervention, 7 patients (64\%) had 1 or more drug treatment failures, meaning they had adverse side effects, the medication had no effect, or the medication had become ineffective over time. After using the IBD-AID, which was the only additional intervention added, all (100\%) of the patients worked with their gastroenterologists to downscale their medication regimen and all $(100 \%)$ of the patients had their IBD symptoms reduced. Of the $\mathrm{CD}$ patients, the baseline HBI averaged 11 (range 1 to 20), and after dietary intervention, the HBI averaged 1.5 (range 0 to 3 ). The UC patients had a mean baseline score of MTLWSI of 7 (range 6 to 8 , with one patient unable to report baseline), and their mean follow-up score was 0 . The mean decrease in the HBI was 9.5 and the mean decrease in the MTLWSI was 7 (Table 1).

\section{Discussion}

Our data suggest that at least some of our patients with inflammatory bowel disease can benefit from the use of the IBD-AID, particularly in terms of reducing symptomatology and consequently a reduction in the use of medication. A portion (33\%) of patients who were offered the diet declined initiation, and of those who decided to participate, many encountered behavioral and intellectual barriers that are to be expected with any comprehensive change in dietary lifestyle. The assistance of a partner also trained in the IBD-AID was clearly beneficial [31]. In the current study, due to small numbers of patients and the case series study design, we were unable to confirm our hypothesized mechanisms of action by examining the impact of the IBD-AID on the intestinal microbiome. However, as deep sequencing and other techniques for defining the microbiome become less expensive this may prove an objective measure of the benefit not only of the IBD-AID, but other diets as well; particularly if the microbiome can be shown to normalize as mucosal healing occurs.

Studies have suggested that IBD results from an inappropriate activation of the mucosal immune system in a genetically susceptible host [30]. The intraluminal gut flora appears to play a role in the inflammatory response and pathogenesis of IBD [32]. A study of patients with UC revealed that bifidobacteria populations are approximately 30 times lower than that of healthy individuals, indicating a dysbiosis that may potentially alter inflammatory responses $[33,34]$. However, it is unclear whether the change in flora is primary, or secondary to the disease. Diet has been shown to influence the balance of the intestinal flora [35]; therefore, it is conceivable that altering the diet can impact the inflammatory response [36].

Mucosal healing potential is another aspect of the IBDAID [37]. Minimizing irritants, while increasing nutrient delivery in a phased manner, (see Table 2) according to patient symptomology is an important consideration to the diet. This is derived from the success of treatment of IBD with tube feeding as opposed to simply nothing by mouth (NPO) [38]. Nutritional deficiencies can result from reduced oral intake, malabsorption, medication side effects and systemic inflammation due to active disease $[38,39]$. In $\mathrm{CD}$, the natural history of disease progression is a significant increase in complicated disease (from $<29 \%$ patients at initial diagnosis having stricturing or penetrating disease to $88 \%$ of patients at 20 years) [40].

The Specific Carbohydrate Diet (SCD, from which the IBD-AID was derived and augmented) was developed by Dr. Sydney Valentine Haas and Dr. Merrill P Hass for the treatment of celiac disease in the mid- $20^{\text {th }}$ century [41], and was later popularized as a treatment for IBD via the internet and lay population [42]. This nutritional regimen eliminates all grains, and encourages ingestion of probiotics in the form of homemade yogurt. The IBDAID diet is not designed around avoidance of gluten, and strives to address other micro- and macronutrients not addressed in the SCD. The food supply, processing and transport of foods have changed dramatically since the inception of the SCD. The IBD-AID also modifies fatty acids, specifically decreasing the total and saturated fats and eliminating hydrogenated oils, and encouraging the increased intake of foods with omega-3 fatty acids. The IBD-AID also differs from the SCD with the inclusion of oats, since oats (and possibly other fermentable grains that provide a substrate for probiotics) [43] appear to be well tolerated and indeed are useful in regulation of bowel frequency and consistency [44].

The IBD-AID is a dietary pattern for which the mechanism and efficacy have yet to be elucidated. Poorly digested complex carbohydrates (even those with defined pre-biotic properties) may lead to bacterial overgrowth and bowel injury with increased intestinal permeability. The waste products of fermentation of undigested carbohydrates include methane, carbon dioxide, hydrogen, lactic and acetic acid, which are all gastrointestinal irritants. The carbohydrates allowed on the original diet are monosaccharides, that is, they have a molecular structure which allows 
intestinal absorption without additional enzymatic degradation. Improvement of nutritional status and alteration in ileo-colonic flora by certain foods is theorized to lead to decreased mucosal inflammation $[2,45]$. There has been an increase in publications over the past ten years with regard to food-based strategies used to alter the intestinal microflora as an alternative or adjunctive therapy for the treatment of IBD. The altered bacteria in the microbiome of IBD patients is said to drive inflammatory responses, [21,24] and there are a growing number of articles linking particular foods that influence the intestinal microbiome, by withholding certain foods that are not well tolerated by patients, or introducing others that can improve symptoms [46].

The dietary pattern of the IBD-AID is carefully oriented to decrease inflammation $[14,15]$ and improve nutritional status, and thought to maintain a beneficial intestinal bacterial balance; however, this has yet to be proven by rigorous scientific examination. The current case series is promising, but must be followed with rigorous research and standardized study design to detect molecular markers of inflammatory and histopathological changes to correlate with clinical outcomes.

The IBD-AID can be difficult and restrictive diet; with adherence largely dictated by personal motivation, support from family and friends, and skills in the kitchen and the marketplace. Consultation and continued support from a knowledgeable dietitian may enhance compliance with the diet.

\section{Conclusion}

Physicians are not provided with specific dietary treatments to offer their IBD patients [47], and recommendations for normal diet are often based upon a philosophy of "if it hurts, don't do it". This case series serves to highlight the importance of dietary manipulation as an adjunct to the limited existing management options for IBD. The study of the IBD-AID would benefit from the rigorous analysis provided by a randomized clinical trial, with evaluation of mucosal healing and assessment of change in gut flora to examine the exact mechanism(s) of benefit.

\section{Competing interests}

The authors declare that they have no competing of interests.

\section{Authors' contributions}

The authors declare they have no competing interests. BO, TS, and DC conceived of the study, and saw the patients, and all authors helped to draft the manuscript. BO further developed the diet, and GP has been invaluable in the teaching kitchen, KB provided medical record extraction. YM provided statistical and epidemiological expertise to summarize results of this study. DC provided critical oversight and clinical supervision. All authors have read and approved the final manuscript.

\section{Acknowledgements}

We thank for the patients and staff for their participation in the IBD-AID case series reports. Y.M. and BO were supported by grant1 \#1R01HL094575-01A1 from the National Heart, Lung, and Blood Institute.

\section{Author details}

'Division of Preventive and Behavioral Medicine, University of Massachusetts Medical School, 55 Lake Ave North, Shaw Building, Worcester MA, USA. 2Department of Gastroenterology, (UMass) Memorial Medical Center, 55 Lake Ave North, Worcester, MA, USA. ${ }^{3}$ Department of Medicine and Pediatrics, UMass Memorial Medical Center, Worcester, MA, USA.

Received: 16 June 2013 Accepted: 7 January 2014

Published: 16 January 2014

\section{References}

1. Day AS, Ledder O, Leach ST, Lemberg DA: Crohn's and colitis in children and adolescents. World J Gastroenterol 2012, 18:5862-5869.

2. Brown AC, Rampertab SD, Mullin GE: Existing dietary guidelines for Crohn's disease and ulcerative colitis. Expert Rev Gastroenterol Hepatol 2011, 5:411-425.

3. Balfour Sartor R: Probiotics for Gastrointestinal Diseases, UpToDate 2013. UpToDate 2013.Location: 95 Sawyer Rd. Waltham, MA; 2013:02453.

4. B| AO: Fecal Microbiota Tranplantation. Curr Opin Gastroentero/ 2013, 29(1):79-84.

5. Roses RE, Rombeau JL: Recent trends in the surgical management of inflammatory bowel disease. World J Gastroenterol 2008, 14:408-412.

6. Fazio WW, Ziv Y, Church JM, Oakley JR, Lavery IC, Milsom JW, Schroeder TK: lleal pouch-anal anastomoses complications and function in 1005 patients. Ann Surg 1995, 222:120-127.

7. Hahnloser D, Pemberton JH, Wolff BG, Larson DR, Crownhart BS, Dozois RR: Results at up to 20 years after ileal pouch-anal anastomosis for chronic ulcerative colitis. Br J Surg 2007, 94:333-340.

8. Bassi A, Dodd S, Williamson P, Bodger K: Cost of illness of inflammatory bowel disease in the UK: a single centre retrospective study. Gut 2004, 53:1471-1478.

9. Carter MJ, Lobo AJ, Travis SP, IBD Section, British Society of

Gastroenterology: Guidelines for the management of inflammatory bowel disease in adults. Gut 2004, 53(Suppl 5):V1-V16.

10. Yamamoto T: Nutrition and diet in inflammatory bowel disease. Curr Opin Gastroenterol 2013, 29:216-221.

11. Triggs CM, Munday K, Hu R, Fraser AG, Gearry RB, Barclay ML, Ferguson LR: Dietary factors in chronic inflammation: food tolerances and intolerances of a New Zealand Caucasian Crohn's disease population. Mutat Res 2010, 690:123-138.

12. Pearson M, Teahon K, Levi AJ, Bjarnason I: Food intolerance and Crohn's disease. Gut 1993, 34:783-787.

13. Haas SV, Haas MP: Management of celiac disease. Lippincott, Philadelphia; 1951.

14. Shivappa N, Steck SE, Hurley TG, Hussey JR, Hebert JR: Designing and developing a literature-derived, population-based dietary inflammatory index. Public Health Nutr 2013, 14:1-8.

15. Cavicchia PP, Steck SE, Hurley TG, Hussey JR, Ma Y, Ockene IS, Hebert JR: A new dietary inflammatory index predicts interval changes in serum high-sensitivity C-reactive protein. J Nutr 2009, 139:2365-2372.

16. Lichtiger S, Present DH, Kornbluth A, Gelernt I, Bauer J, Galler G, Michelassi F, Hanauer S: Cyclosporine in severe ulcerative colitis refractory to steroid therapy. N Engl J Med 1994, 330:1841-1845.

17. Vermeire S, Schreiber S, Sandborn WJ, Dubois C, Rutgeerts P: Correlation between the Crohn's disease activity and Harvey-Bradshaw indices in assessing Crohn's disease severity. Clin Gastroenterol Hepatol 2010, 8:357-363.

18. Tamboli CP, Neut C, Desreumaux P, Colombel JF: Dysbiosis in inflammatory bowel disease. Gut 2004, 53:1-4.

19. O'Flaherty S, Saulnier DM, Pot B, Versalovic J: How can probiotics and prebiotics impact mucosal immunity? Gut Microbes 2010, 1:293-300.

20. Fujimori S, Gudis K, Mitsui K, Seo T, Yonezawa M, Tanaka S, Tatsuguchi A, Sakamoto C: A randomized controlled trial on the efficacy of synbiotic versus probiotic or prebiotic treatment to improve the quality of life in patients with ulcerative colitis. Nutrition (Burbank, Los Angeles County, Calif 2009, 25:520-525.

21. Bosscher D, Breynaert A, Pieters L, Hermans N: Food-based strategies to modulate the composition of the intestinal microbiota and their associated health effects. J Physiol Pharmacol 2009, 60(Suppl 6):5-11.

22. Jia W, Whitehead RN, Griffiths L, Dawson C, Waring RH, Ramsden DB, Hunter $\mathrm{JO}$, Cole JA: Is the abundance of Faecalibacterium prausnitzii relevant to Crohn's disease? FEMS microbiology letters 2010, 310:138-144.

23. McFarland LV: Systematic review and meta-analysis of Saccharomyces boulardii in adult patients. World J Gastroenterol 2010, 16(18):2202-2222.

24. Furrie E, Macfarlane S, Kennedy A, Cummings JH, Walsh SV, O'Neil DA, Macfarlane GT: Synbiotic therapy (Bifidobacterium longum/Synergy 1) 
initiates resolution of inflammation in patients with active ulcerative colitis: a randomised controlled pilot trial. Gut 2005, 54:242-249.

25. Lorea Baroja M, Kirjavainen PV, Hekmat S, Reid G: Anti-inflammatory effects of probiotic yogurt in inflammatory bowel disease patients. Clin Exp Immunol 2007, 149:470-479.

26. Hou JK, Abraham B, El-Serag H: Dietary intake and risk of developing inflammatory bowel disease: a systematic review of the literature. Am J Gastroenterol 2011, 106:563-573.

27. Guerreiro CS, Ferreira P, Tavares L, Santos PM, Neves M, Brito M, Cravo M: Fatty acids, IL6, and TNFalpha polymorphisms: an example of nutrigenetics in Crohn's disease. Am J Gastroenterol 2009, 104:2241-2249.

28. Triantafillidis JK, Merikas E, Georgopoulos F: Current and emerging drugs for the treatment of inflammatory bowel disease. Drug Des Devel Ther 2011, 5:185-210.

29. Wall R, Ross RP, Fitzgerald GF, Stanton C: Fatty acids from fish: the anti-inflammatory potential of long-chain omega-3 fatty acids. Nutrition reviews 2010, 68:280-289.

30. Guijarro LG, Mate J, Gisbert JP, Perez-Calle JL, Marin-Jimenez I, Arriaza E, Olleros T, Delgado M, Castillejo MS, Prieto-Merino D, Gonzalez Lara V, Pena AS: N-acetyl-L-cysteine combined with mesalamine in the treatment of ulcerative colitis: randomized, placebo-controlled pilot study. World J Gastroenterol 2008, 14:2851-2857.

31. Choi JH, Chung KM, Park K: Psychosocial predictors of four healthpromoting behaviors for cancer prevention using the stage of change of Transtheoretical Model. Psycho-Oncology 2013, 29(22):2253-2261.

32. Podolsky DK: The future of IBD treatment. J Gastroenterol 2003 38(Suppl 15):63-66

33. Sheil B, Shanahan F, O'Mahony L: Probiotic effects on inflammatory bowel disease. J Nutr 2007, 137:819S-824S.

34. Schwiertz A, Jacobi M, Frick JS, Richter M, Rusch K, Kohler H: Microbiota in pediatric inflammatory bowel disease. J Pediatr 2010, 157:240-244.e1.

35. Galland L: Rakel: Integrative Medicine. 2nd edition. Philadelphia: Saunders Elsevier; 2007

36. Paturi G, Mandimika T, Butts CA, Zhu S, Roy NC, McNabb WC, Ansell J: Influence of dietary blueberry and broccoli on cecal microbiota activity and colon morphology in mdr1a(-/-) mice, a model of inflammatory bowel diseases. Nutrition 2012, 28(3):324-330.

37. Osterman M: Mucosal healing in inflammatory bowel disease. J Clin Gastroenterol 2013, 47(3):212-221

38. Massironi S, Rossi R, Cavalcoli F, Della Valle S, Fraquell IM, Conte D: Nutritional deficiencies in inflammatory bowel disease: Therapeutic approaches. Clin Nutr 2013, S0261-5614(13):00098-8.

39. Donnellan C, Yann L, Lal S: Nutritional management of Crohn's disease. Therap Adv Gastroenterol 2013, 6(3):231-242.

40. Thia KT, Sandborn WJ, Harmsen WS, Zinsmeister AR, Loftus EV Jr: Risk factors associated with progression to intestinal complications of Crohn's disease in a population-based cohort. Gastroenterology 2010, 139:1147-1155.

41. Haas SV, Haas MP: The treatment of celiac disease with the specific carbohydrate diet; report on 191 additional cases. Am J Gastroenterol 1955, 23:344-360.

42. Gottschall E: Breaking the Vicious Cycle: Intestinal Health through Diet. Baltimore, Ontario: Kirkton Press Ltd; 2004.

43. Roberfroid M: Prebiotics: the concept revisited. J Nutr 2007, 137:830S-837S

44. Comino I, Real A, de Lorenzo L, Cornell H, Lopez-Casado MA, Barro F, Lorite $\mathrm{P}$, Torres MI, Cebolla A, Sousa C: Diversity in oat potential immunogenicity: basis for the selection of oat varieties with no toxicity in coeliac disease. Gut 2011, 60:915-922.

45. Hardy H, Harris J, Lyon E, Beal J, Foey AD: Probiotics, prebiotics and immunomodulation of gut mucosal defences: homeostasis and immunopathology. Nutrients 2013, 5:1869-1912.

46. Tilg H: Diet and intestinal immunity. N Engl J Med 2012, 366:181-183.

47. Cohen AB, Lee D, Long MD, Kappelman MD, Martin CF, Sandler RS, Lewis JD: Dietary patterns and self-reported associations of diet with symptoms of inflammatory bowel disease. Dig Dis Sci 2013, 58:1322-1328.

doi:10.1186/1475-2891-13-5

Cite this article as: Olendzki et al:: An anti-inflammatory diet as treatment for inflammatory bowel disease: a case series report . Nutrition Journal 2014 13:5.

\section{Submit your next manuscript to BioMed Central and take full advantage of:}

- Convenient online submission

- Thorough peer review

- No space constraints or color figure charges

- Immediate publication on acceptance

- Inclusion in PubMed, CAS, Scopus and Google Scholar

- Research which is freely available for redistribution 